\title{
Electrical response of the Summit-Greenland ice core to ammonium, sulphuric acid, and hydrochloric acid
}

\author{
John C. Moore ${ }^{1}$ and Eric W. Wolff \\ British Antarctic Survey, Natural Environment Research Council, Cambridge, UK \\ Henrik B. Clausen and Claus U. Hammer \\ Niels Bohr Institute, Department of Geophysics, University of Copenhagen, Denmark \\ Michel R. Legrand \\ Laboratoire de Glaciologie et Géophysique de l'Environnement, Grenoble, France
}

Katrin Fuhrer

Physikalisches Institut, Universität Bern, Switzerland

\begin{abstract}
Electrical and chemical analysis of the GRIP ice core from Summit in central Greenland confirms that the ECM current is controlled solely by acids in the ice, though there could be different responses for different acids. The dielectric conductivity is dependent on strong acid, on sea salt chloride, and also on ammonium concentrations in the ice. The response to $\mathrm{NH}_{4}{ }^{+}$is similar to that of sea salt chloride, as they both conduct only at $\mathrm{AC}$ frequencies, but $\mathrm{NH}_{4}{ }^{+}$is approximately twice as conductive per mole. The response to the strong acids shows results consistent with earlier work, with similar responses throughout the length of the core. It seems as if all the thousands of electrical peaks in the GRIP core may be explained by the response to just three chemical species: acidity, ammonium salts, and a third component which is probably chloride.
\end{abstract}

\section{Introduction}

It has become apparent that changes in chemical impurity concentration are responsible for most of the variability of both the DC and LF conductivity of polar ice [Moore et al., 1992a], although other ice properties may be relevant, particularly above the firn-ice transition. The DC conductivity, effectively measured by the ECM (electrical conductivity measurement) method [Hammer, 1980] is controlled by the acidity of the ice; very high salt concentrations have no effect. At higher frequencies (as measured by the dielectric profiling (DEP) method [Moore and Paren, 1987]), previous work showed that both acids and some component (probably chloride) of sea salt [Moore et al., 1992b] contribute.

The $3028 \mathrm{~m}$ GRIP (Greenland Ice Core Project) core spans at least the last complete climatic cycle [GRIP Project Members, 1993] and presents the opportunity to study both the DC and LF properties of natural ice containing a wide range of chemical impurities. This paper shows additional evidence of the

${ }^{1}$ Now at Arctic Institute, University of Lapland, Rovaniemi, Japan.

Copyright 1994 by the American Geophysical Union.

Paper number 94GL00542

0094-8534/94/94GL-00542\$03.00 importance of impurities, and introduces a quantitative description of the electrical effect of a further chemical species, ammonium.

The LF electrical properties of the ice were measured at $2 \mathrm{~cm}$ resolution with an updated version of the $\mathrm{AC}$ dielectric profiling technique (DEP) [Moore and Paren, 1987]. The conductance and capacitance were measured at a range of frequencies from $120 \mathrm{~Hz}$ to $300 \mathrm{kHz}$ for each $2 \mathrm{~cm}$ section. From a range of properties that can be derived, $\sigma_{\infty}$ (the high-frequency limit of the conductivity) has proved to be the most useful, and is reported throughout this paper. Measurements were carried out on the entire core from $138 \mathrm{~m}$ down in the field at a range of temperatures between -25 and $-10^{\circ} \mathrm{C}$. The data have been normalized to a reference temperature of $-15^{\circ} \mathrm{C}$, using an activation energy of $0.5 \mathrm{eV}\left(48 \mathrm{~kJ} \mathrm{~mol}^{-1}\right)$ to correct the background part of the conductivity that is due to pure ice, and 0.22 $\mathrm{eV}$ (the average for salt and acid from previous studies) to correct everything above this background level [Moore et al, 1992b]. There were some difficulties with this correction because at some depths the temperature of the ice was sometimes still equilibrating when our measurements were made, so that the ice temperature is poorly known.

In ECM, a high DC voltage $(1250 \mathrm{~V})$ is applied between two electrodes that are run along a fresh, flat surface, and the current flowing between them is measured [Hammer, 1980]. ECM was carried out at a resolution of a few $\mathrm{mm}$, and data were corrected to $-14^{\circ} \mathrm{C}$ using an activation energy of $0.23 \mathrm{eV}$. Current data have been converted to $\mathrm{H}^{+}$concentrations using the calibration discussed later. Chemical analyses for a range of ions $\left(\mathrm{Na}^{+}\right.$, $\mathrm{NH}_{4}^{+}, \mathrm{K}^{+}, \mathrm{Ca}^{2+}, \mathrm{Mg}^{2+}, \mathrm{F}-\mathrm{Cl}^{-}, \mathrm{NO}_{3}^{-}, \mathrm{SO}_{4}{ }^{2-}, \mathrm{HCOO}-$ (formate), $\mathrm{CH}_{3} \mathrm{COO}-$ (acetate), $\mathrm{CH}_{3} \mathrm{SO}_{3}^{-}$(methanesulphonate), and $\mathrm{C}_{2} \mathrm{O}_{4}{ }^{2-}$ (oxalate)) were done by ion chromatography on discrete samples, typically $5 \mathrm{~cm}$ in length. At present only a small fraction of the core has been chemically analysed. The main species not directly measured was $\mathrm{H}^{+}$, but we can use the ECM technique which is only sensitive to acidity [Moore et al., 1992a], to derive this electrically important species. Ammonia was measured continuously in the field at a few mm resolution by a continuous flow technique [Fuhrer et al., 1993]. Suitable depth-averaging allows direct comparisons between the various records.

Both the ECM and DEP $\sigma_{\infty}$ records show many individual peaks (often representing less than a year's snowfall) 
superimposed on a background that varies with climate. The ECM background is high in acidic ice, and low in alkaline ice. The small ECM signal in alkaline ice decreases still further as the ice becomes more alkaline, and this will be discussed elsewhere. Peaks in ECM are normally due to volcanic sulphuric acid, but sometimes $\mathrm{HCl}$ is also present. For DEP, there is a conductivity (expected to be $9 \mu \mathrm{S} \mathrm{m}^{-1}$ at $-15^{\circ} \mathrm{C}$ ) due to pure ice. On top of that is again a background that varies with climate, and peaks that are due to volcanic and other input. All large peaks and trends in ECM can be seen in the DEP, but additional ones due to other components (discussed later) are also present.

\section{Ammonium}

Legrand et al. [1992] report the occurrence of occasional large peaks (up to $20 \mu \mathrm{M}$ concentrations) in ammonium formate during the Holocene part of the GRIP core. There are also smaller annual peaks in ammonium concentration. Large ammonium peaks give drops in the ECM current, and peaks in the DEP conductivity (Figure 1). The ECM drop implies that the acidity falls, or that the ice may even be alkaline, as is verified by detailed chemical ion balances on a few of the ammonium peaks. Although $\mathrm{NH}_{4}{ }^{+}$has previously been included in a statistical analysis of the ECM response to chemistry [Taylor et al., 1992], we find no evidence that it has any effect other than that of neutralising the acid that would otherwise be present.

Continuous ammonium data are available but their quantitative accuracy is not yet fully verified. In the Younger Dryas period, where acidity is low due to neutralisation by carbonate dust, ammonium is clearly the main cause of peaks in the DEP $\sigma_{\infty}$ (Figure 2). From analysis of the few peaks measured by ion-chromatography, $\sigma_{\infty}\left(\mathrm{S} \mathrm{m}^{-1}\right)$ appears linearly related to $\left[\mathrm{NH}_{4}{ }^{+}\right]$(molar concentration) by:

$$
\sigma_{\infty}=1.0\left[\mathrm{NH}_{4}^{+}\right]
$$

at $-15^{\circ} \mathrm{C}$ assuming that the activation energy of $0.22 \mathrm{eV}$ used for $\sigma_{\infty}$ applies also to $\mathrm{NH}_{4}{ }^{+}$signals. However, the coarse chemical sampling procedure makes precise calibration difficult and the variability in the coefficient between different events is about $20 \%$.

We must explain how the ammonium salts can produce a change in $\sigma_{\infty}$ while leaving the ECM current and therefore the

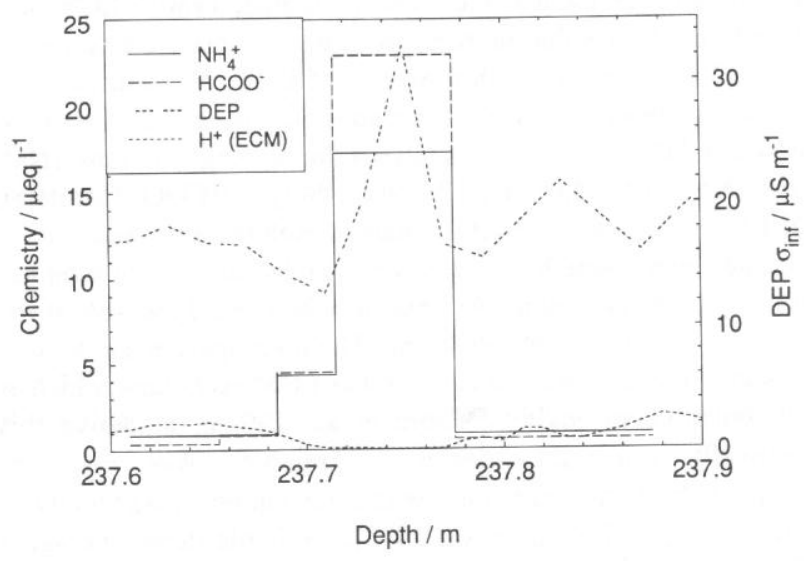

Figure 1. DEP and ECM profile over an ammonium formate peak at $237.7 \mathrm{~m}$. The ECM signal drops as DEP rises.

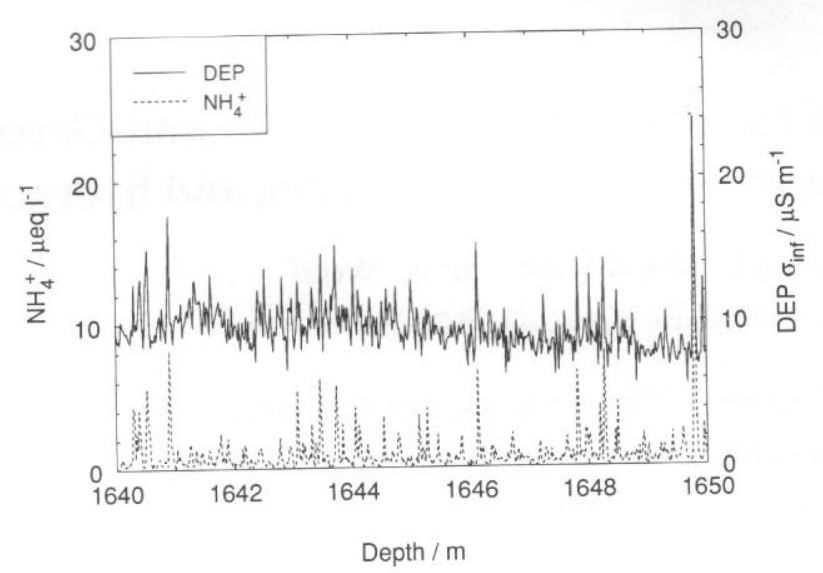

Figure 2. DEP and ammonium (by continuous flow) profiles for a $10 \mathrm{~m}$ section of the Younger Dryas ice.

DC conductivity unaltered. The coefficient in (1) is approximately twice the coefficient $\left(0.55\right.$ at $\left.-15^{\circ} \mathrm{C}\right)$ found for seasalt $\mathrm{Cl}$ [Moore et al., 1992b], which also affects only the AC conductivity of ice. Moore et al. [1992b] interpret the electrical effect of sea-salt $\mathrm{Cl}$ using the Jaccard theory (see for example Petrenko [1993]) of electrical conduction in ice. The $\mathrm{Cl}^{-}$ions are incorporated into the ice lattice with the production of Bjerrum L defects. Bjerrum defects are the majority electrical charge carriers in ice at temperatures encountered in natural ice sheets, and consequently determine only the $\mathrm{AC}$ conductivity. The expression for the AC conductivity $\left(\sigma_{\infty}\right)$ in Jaccard theory is

$$
\sigma_{\infty}=n_{L} \mu_{L}\left|e_{L}\right|+n_{D} \mu_{D}\left|e_{D}\right|
$$

where the subscripts $\mathrm{L}$ and $\mathrm{D}$ refer to the Bjerrum $\mathrm{L}$ and $\mathrm{D}$ defects respectively, $\mathrm{n}$ is the concentration of the species, e its charge, and $\mu$ its mobility.

In the larger $\mathrm{NH}_{4}{ }^{+}$spikes, $\mathrm{NH}_{4}{ }^{+}$seems to be present as ammonium formate, although other anions could be important in the more frequent smaller peaks. No laboratory data exist on the electrical properties of ice doped with ammonium formate, though the behaviour of ice containing $\mathrm{NH}_{4}{ }^{+}$has been studied [Gross et al., 1978]. Ammonium formate will be dissociated in water to the very polar ions $\mathrm{NH}_{4}{ }^{+}$and $\mathrm{HCOO}^{-}$. The covalent radius of $\mathrm{N}$ is close to that of $\mathrm{O}$ and it is expected that either $\mathrm{NH}_{3}$ or $\mathrm{NH}_{4}{ }^{+}$may be substitutionally incorporated into the ice lattice for an $\mathrm{H}_{2} \mathrm{O}$. The one or two excess protons introduced would then behave as 1 or $2 \mathrm{D}$ defects in the lattice; depending on the affinity of the protons for the $\mathrm{N}$ centre, $\mathrm{NH}_{4}{ }^{+}$might also lead to the formation of an ionisation defect, but the lack of a DC signal suggests this is not significant. It is possible to imagine the relatively small $\mathrm{HCOO}^{-}$ion fitting within the ice lattice and causing L defect propagation, but this requires further investigation.

We therefore could have up to $2 \mathrm{D}$ defects (and perhaps $1 \mathrm{~L}$ defect) produced for each ammonium in the ice. Jaccard theory requires that $e_{L}=-e_{D}$, and experimental measurements suggest $\mathrm{e}_{\mathrm{D}} / \mathrm{e}=0.37$ [Petrenko, 1993] (e is $1.6 \times 10^{-19} \mathrm{C}$ ). From measurements on ice doped with $\mathrm{HF}$ impurity, at $-15^{\circ} \mathrm{C}, \mu_{\mathrm{L}}=1.8$ x $10^{-8} \mathrm{~m}^{2} \mathrm{~V}^{-1} \mathrm{~s}^{-1}$ [average of Camplin et al., 1978 and Jaccard, 1959]. No values for $\mu_{D}$ are reported in the literature, though it 
has been shown that $\mu_{\mathrm{D}} \leq \mu_{\mathrm{L}}$ [Petrenko, 1993]. From equation (2) we can obtain a value for $\mathrm{k}$ in an equation of the form:

$$
\sigma_{\infty}=\mathrm{k}\left[\mathrm{NH}_{4}^{+}\right]=\left(\mathrm{k}_{\mathrm{L}} \mathrm{N}_{\mathrm{L}}+\mathrm{k}_{\mathrm{D}} \mathrm{N}_{\mathrm{D}}\right)\left[\mathrm{NH}_{4}{ }^{+}\right]
$$

where $\mathrm{N}_{\mathrm{L}}$ and $\mathrm{N}_{\mathrm{D}}$ are the number of $\mathrm{L}$ and $\mathrm{D}$ defects introduced per ammonium ion present, and the other units are as in equation (1). From equation (2), $\mathrm{k}_{\mathrm{L}}=0.66$, while $\mathrm{k}_{\mathrm{D}} \leq 0.66$.

The observed coefficient (1) for the GRIP core at $-15^{\circ} \mathrm{C}$ is 1.0 . With this coefficient we appear to need at least the formation of 2 $\mathrm{D}$ defects (with $>75 \%$ efficiency of defect generation). Moore et al., [1992b] found that $\mathrm{L}$ defects were generated by $\mathrm{Cl}$ - ions at an efficiency of about $70 \%$. Because of the uncertainty in the value of $\mu_{D}$, it may be that only $\mathrm{D}$ defects are produced, but we cannot exclude the possibility that the anion (HCOO- in larger peaks) is incorporated in the lattice. If $\mu_{\mathrm{D}} \ll \mu_{\mathrm{L}}$, then $\mathrm{L}$ defect formation would certainly be required.

\section{Acids}

Ion balance calculations of the measured anions and cations were used to give an estimate of $\left[\mathrm{H}^{+}\right]$. In general, the background acidity in Holocene Greenland ice is mainly $\mathrm{HNO}_{3}$, with large peaks due mainly to volcanic eruptions which usually deposit mostly $\mathrm{H}_{2} \mathrm{SO}_{4}$, but occasionally are dominated by $\mathrm{HCl}$. The original ECM calibration $\left(\left[\mathrm{H}^{+}\right]=0.045 \mathrm{I}^{1.73}\right)$ [Hammer, 1980] is not good for ice cores taken recently from the central areas of Greenland, and Moore et al. [1992a] published a different calibration based on a short section of Greenland ice core containing the Laki large volcanic signal. Comparisons of the ECM and chemical data across volcanic peaks in the GRIP core shows that they fit poorly to the original calibration [Hammer, 1980]. In Figure 3, we have plotted the ECM current against acidity for 11 volcanic events where chemical data at suitable resolution exist, and for the Laki event at Site G [Moore et al., 1992a]. For the Site $\mathrm{G}$ Laki data, $\mathrm{H}^{+}$was measured directly by acid titration. To calculate $\mathrm{H}^{+}$for the GRIP data, we used either the total ion balance, or the sum of acidic anions. Past experience suggests that, used with care, these parameters give a good agreement with $\mathrm{H}^{+}$measured directly.

There is clearly much scatter, some of which is certainly induced by the method of calculating the chemistry; a more precise calibration must await direct measurements of $\mathrm{H}^{+}$. The two $\mathrm{Cl}$-rich volcanoes (xs $\mathrm{Cl}^{-}>50 \%$ of total acidity) fall well away from the other data. Curves of various forms will fit the data, but Moore et al., [1992a] found a calibration curve of the form $\left[\mathrm{H}^{+}\right]=\mathrm{al}^{\mathrm{b}}+\mathrm{c}$, where $\mathrm{I}$ is ECM current. However, with a positive value of $c$, a poor fit is obtained at low currents and the relationship does not explain the low but significant ECM signal in the alkaline (and therefore negative $\mathrm{H}^{+}$) Wisconsin ice. We have tried to reduce these difficulties by forcing $\mathrm{c}$ to be zero. With the data that we have at present, more complicated calibrations are not justified. Regressions including different volcanic peaks show that the values of $a$ and $b$ are very sensitive, with $b$ values between about 1.6 and 2.7 for various central Greenland datasets. The choice of equation affects mainly the calculated $\mathrm{H}^{+}$values for the very largest volcanic peaks, and the different regressions predict fairly similar $\mathrm{H}^{+}$at typical values of 0.5-5 $\mu \mathrm{M}$. Throughout this paper we use:

$$
\left[\mathrm{H}^{+}\right]=0.03 \mathrm{I}^{2}
$$

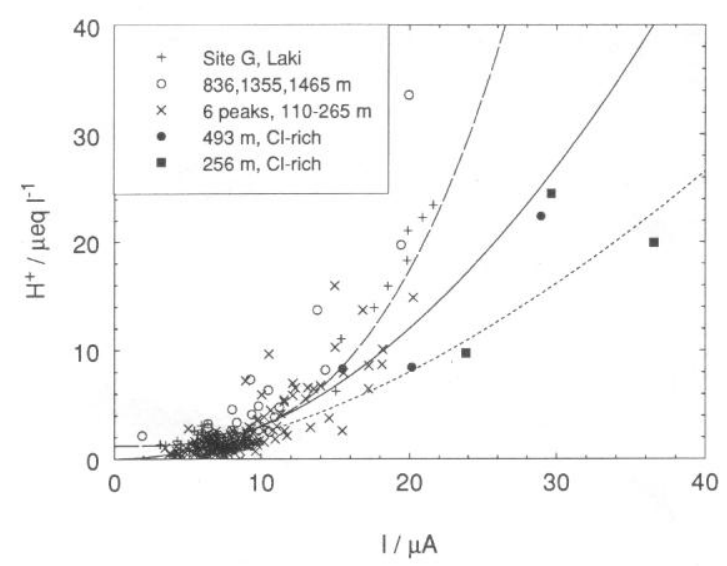

Figure 3. ECM calibration plot. Solid squares and circles show data from volcanic signals where $\mathrm{Cl}^{-}$was a major component. Open circles represent data analysed at Summit, crosses show data analysed in Copenhagen from ice above $300 \mathrm{~m}$ depth. The short-dashed curve represents the Hammer [1980] ECM calibration, the long-dashed curve is the Site G calibration of Moore et al. [1992a], and the solid line is that produced by (4).

Data from the two $\mathrm{Cl}^{-}$-rich peaks fit close to the Hammer [1980] calibration. It has already been suggested [Legrand et al., 1987, Moore et al., 1992a] that $\mathrm{HCl}$ and $\mathrm{HNO}_{3}$ may lead to larger ECM signals than an equivalent $\mathrm{H}^{+}$from $\mathrm{H}_{2} \mathrm{SO}_{4}$, and this would help to explain both the discrepancy, and some part of the curvature of the main calibration. For the remainder of this paper we will use the calibration (4) to calculate $\mathrm{H}^{+}$. Note that we do not yet know the meaning of the relationship seen in alkaline ice (calculated $\mathrm{H}^{+}$ values below about $0.1 \mu \mathrm{M}$ ).

We will now use (4) to investigate the response of the AC conductivity, $\sigma_{\infty}$ to acidity. We show in Figure 4 four sections covering different climatic regions of the core, and different ranges of acidity. The scatterplots show some curvature at low acidity, reflecting in part our ignorance of the calibration in alkali ice. The lines shown are linear regressions of all data above 0.3 $\mu \mathrm{M}$. The coefficient relating a linear fit of $\sigma_{\infty}$ to $\left[\mathrm{H}^{+}\right]$is similar for all four sections $(3.74,5.25,4.51$ and 4.67$)$. The differences between sections are partly due to the different ranges of acidity involved, but are also due largely to differences in values at the low acidity end, where the temperature correction becomes particularly critical because the correction to the pure ice part becomes dominant. At an acidity of $3 \mu \mathrm{M}$, the regressions for all four sections predict $\sigma_{\infty}$ between 25.3 and $26.5 \mu \mathrm{S} \mathrm{m}^{-1}$. Moore et al., [1992a] found a coefficient of 1.8 for the Laki $\mathrm{H}_{2} \mathrm{SO}_{4}$ eruption (Site $\mathrm{G}$ ) at $-22^{\circ} \mathrm{C}$, corresponding to a coefficient of 2.4 at $-15^{\circ} \mathrm{C}$. The coefficient found for the Laki signal is lower than that for the GRIP core here. However, if we take the original ECM data for the Laki core and convert it to $\mathrm{H}^{+}$by (4), the $\sigma_{\infty} / \mathrm{H}^{+}$ coefficient becomes 3.9 at $-15^{\circ} \mathrm{C}$. This shows that the $\sigma_{\infty}-\mathrm{ECM}$ relationship is in good agreement between cores, but that apparent discrepancies arise from the imprecise nature of the calibration of ECM against measured chemistry.

It is encouraging that the vast majority of the data points are above the minimum expected conductivity at $-15^{\circ} \mathrm{C}$ of $9 \mu \mathrm{S} \mathrm{m}^{-1}$, the conductivity of pure ice single crystals [Camplin et al., 1978]. The intercept for the Holocene data set is somewhat higher than expected when the relatively low concentrations of chloride and ammonium in the ice are considered. This may be partly due to 

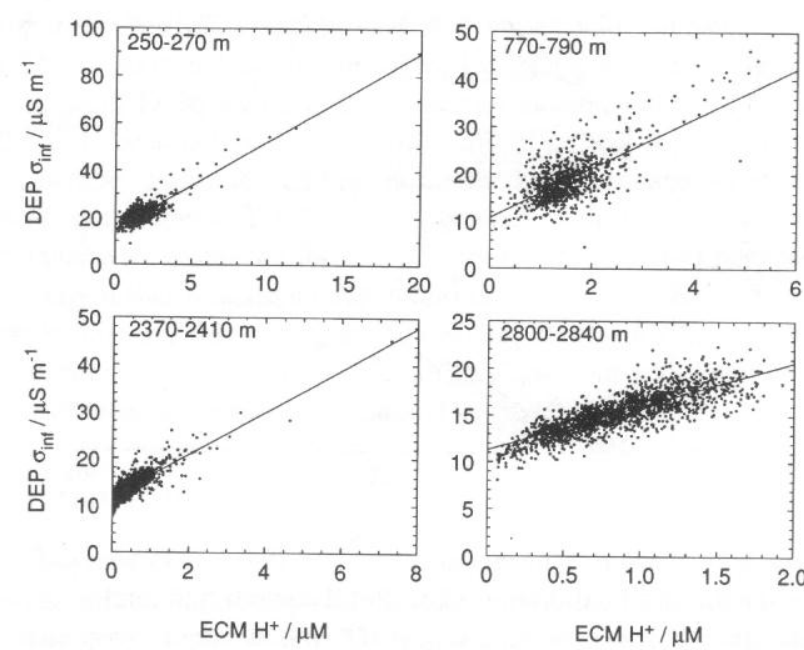

Figure 4. Scattergrams of four separate core sections showing the $\sigma_{\infty}$ - acidity relationship. The acidity was calculated from the ECM data using (4). In each case the lines are the best fits for data above $0.3 \mu \mathrm{M}$ from ECM. The upper two core sections are Holocene ice, the section $2370-2410 \mathrm{~m}$ is a warm interstadial in Wisconsin-age ice, and the $2800-2840 \mathrm{~m}$ section is from ice identified as being in the Eemian interglacial.

problems with the temperature correction (as discussed above), and partly due to some genuine curvature because of the change from mainly $\mathrm{HNO}_{3}$ to $\mathrm{H}_{2} \mathrm{SO}_{4}$ dominance at higher acidities; another possibility is that our chosen ECM calibration is still poor for estimating $\mathrm{H}^{+}$at low acidities.

$\left[\mathrm{H}^{+}\right]$from $\mathrm{HCl}$ in the two peaks investigated produces a stronger response in ECM, but not in DEP, than does an equivalent $\left[\mathrm{H}^{+}\right]$from $\mathrm{H}_{2} \mathrm{SO}_{4}$. The ECM result implies less efficient dissociation of the $\mathrm{H}_{2} \mathrm{SO}_{4}$ than $\mathrm{HCl}$. Possible mechanisms of acid conduction are discussed by Moore et al., [1992a], where the two hypotheses of conduction via a Jaccard mechanism and via concentrated liquid acid at grain boundaries are evaluated. The different response of ECM and DEP is not easy to explain at this stage.

\section{The third component}

Detailed examination shows some peaks in the record that appear to be significant, are not due to acid or ammonia, but seem to be related to peaks in calcium. Since many chemical components in the ice increase more or less in phase with calcium, it is not yet possible to be sure which is responsible for the DEP signal. However, previous work shows that $\mathrm{Cl}^{-}$causes a DEP signal, and it seems probable that this will turn out to be the third factor responsible for DEP signals in the GRIP core. More detailed chemistry will be needed before this can be confirmed.

\section{Conclusion}

Despite the huge quantities of electrical data now available for the GRIP core, more high-resolution chemical data is needed to provide a final quantitative description of the electrical-chemical relationship. However, the evidence here confirms that the ECM (DC) response is controlled by acidity alone, although there remains work to be done to substantiate the suggestion that there is a different response to different acids. This first, and clear, evidence of an AC only signal due to ammonium in natural ice should stimulate theoretical work on the defect formation responsible for the signal. In the GRIP core most of the thousands of DEP $\sigma_{\infty}$ peaks are explained simply by a response to acid, to ammonium salts, and to one of the other species (probably chloride) that varies in phase with $\mathrm{Ca}$ in glacial age ice. This confirms the potential of using the two electrical methods together as a very powerful way of surveying rapidly the general chemical properties of long ice cores, to indicate the form both of the acidity profile and of the variations in other impurities.

Acknowledgements. This work is a contribution to the Greenland Ice Core Project (GRIP), a European Science Foundation programme with eight nations collaborating to drill through the central part of the Greenland ice sheet.

\section{References}

Camplin, G. C., J. W. Glen, and J. G. Paren, Theoretical models for interpreting the dielectric behaviour of HF-doped ice, J. Glaciol., 21, 123-142, 1978.

Fuhrer, K., A. Neftel, M. Anklin, and V. Maggi, Continuous measurements of hydrogen peroxide, formaldehyde, calcium and ammonium concentrations along the new GRIP ice core from Summit, central Greenland, Atmos. Envir., 27A, 1873-1880, 1993.

GRIP Project Members, Climate instability during the last interglacial period recorded in the GRIP ice core, Nature, 364, 203-207, 1993.

Gross, G. W., I. C. Hayslip, and R. N. Hay, Electrical conductivity and relaxation in ice crystals with known impurity content, J. Glaciol., 21, 143-160, 1978.

Hammer, C. U., Acidity of polar ice cores in relation to absolute dating, past volcanism, and radio echoes, J. Glaciol., 25, 359-372, 1980.

Jaccard, C., Étude théoretique et experimentale des propriétés électriques de la glace, Helv. Phys. Acta, 32, 89-128, 1959.

Legrand, M. R., J.-R. Petit, and Y.S. Korotkevich, D.C. conductivity of Antarctic ice in relation to its chemistry, J. Phys., 48, C1:605-C1:611, 1987.

Legrand, M., M. De Angelis, T. Staffelbach, A. Neftel, and B. Stauffer, Large perturbations of ammonium and organic acids content in the summit-Greenland ice core. Fingerprint from forest fires?, Geophys. Res. Lett., 19, 473-475, 1992.

Moore, J. C., and J. G. Paren, A new technique for dielectric logging of Antarctic ice cores, J. Phys., 48, C1:155-C1:160, 1987.

Moore, J.C., E.W. Wolff, C.U. Hammer, and H.B. Clausen, The chemical basis for the electrical stratigraphy of ice, J. Geophys. Res., 97, 1887 $1896,1992 \mathrm{a}$.

Moore, J.C., J.G. Paren, and H. Oerter, Sea salt dependent electrical conduction in polar ice, J. Geophys. Res., 97, 19803-19812, 1992b.

Petrenko, V.F., Electrical properties of ice, Special Rep. 93-20, 80 pp., US Army CRREL, Hanover, New Hampshire, 1993.

Taylor, K., R. Alley, J. Fiacco, P. Grootes, G. Lamorey, P. Mayewski, and M.J. Spencer, Ice-core dating and chemistry by direct-current electrical conductivity, J. Glaciol., 38, 325-332, 1992.

John C. Moore, Arctic Institute, University of Lapland, Box 122, SF96101 Rovaniemi, Finland. (e-mail: jmoore@ roisrv.urova.fi)

Eric W. Wolff, British Antarctic Survey, High Cross, Madingley

Road, Cambridge CB3 0ET, UK. (e-mail: u_eww@vaxc.nerc-bas.ac.uk) Henrik B. Clausen and Claus U. Hammer, Niels Bohr Institute, Department of Geophysics, Haraldsgade 6, DK-2200 Copenhagen N, Denmark.

Michel R. Legrand, Laboratoire de Glaciologie et Géophysique de l'Environnement, BP 96, 38402 Saint Martin d'Hères Cedex, France.

Katrin Fuhrer, Physikalisches Institut, Universität Bem, Sidlerstrasse 5, CH-3012 Bern, Switzerland. e-mail: kfuhrer@phil.unibe.ch)

(Received October 23, 1993;

accepted January 31, 1994.) 